\title{
Lymphoepithelioma-Like Carcinoma of the Uterine Cervix: A Case Report
}

Raouah Mehdi ${ }^{1}$, Oumalloul Basma ${ }^{2}$, Makrane Dounia ${ }^{2}$, Laatitioui Sana ${ }^{1}$, Igarramen Tariq ${ }^{1}$, Bouchabaka Yassine ${ }^{1}$, Saadoune Mohamed ${ }^{1}$, El Matlini Abdelali ${ }^{1}$, Bounid Oumayma ${ }^{1}$, Darfaoui Mouna ${ }^{1}$, Lalya Issam ${ }^{1}$, El Omarani Abdelahamid $^{1}$, Khouchani Mouna ${ }^{1}$

${ }^{1}$ Department of Radiation Oncology, Mohammed VI University Hospital, Marrakech, Morocco

${ }^{2}$ Department of Obstetrics and Gynecology, Mohammed VI University Hospital, Marrakech, Morocco

DOI: $\underline{10.36347 / \text { sjmcr.2020.v08i04.020 }}$

| Received: 15.04.2020 | Accepted: 25.04.2020 | Published: 28.04.2020

*Corresponding author: Raouah Mehdi

Abstract

Case Report

Lymphoepithelioma-like carcinoma (LELC) occurring in the reproductive organs is a rare variant of squamous cell carcinoma, and this tumor of the uterine cervix accounts for $0.7 \%$ of all primary cervical uterine neoplasms. It differs from the usual squamous cell carcinoma of the cervix in its morphology and clinical behavior. We report a case of LELC of cervix (FIGO stage IIB) in a 51 year old woman who presented with three months history of postcoital bleeding per vaginum and was treated primarily with concurrent chemoradiotherapy (CCRT), and brachytherapy. The prognosis of uterine lymphoepithelioma-like carcinoma is thought to be better than those of other cervical cancer types, but careful follow-up at fixed intervals is recommended. The patient has been followed up for 9 months since the end of radiation therapy, during which time there has been no evidence of tumor recurrence or metastasis.

Keywords: Lymphoepithelioma-like carcinoma, uterine cervix, concurrent chemoradiotherapy, case report. Copyright @ 2020: This is an open-access article distributed under the terms of the Creative Commons Attribution license which permits unrestricted use, distribution, and reproduction in any medium for non-commercial use (NonCommercial, or CC-BY-NC) provided the original author and source are credited.

\section{INTRODUCTION}

Lymphoepithelioma carcinoma is most common in the nasopharynx. A similar tumor known as lymphoepithelioma-like carcinoma is generally seen in the stomach, salivary gland, and lung [1]. Lymphoepithelioma-like carcinoma occurring in the uterine cervix is very rare, and was first reported by Hamazaki et al. in 1968 [2]. Lymphoepithelioma-like carcinoma of the uterine cervix accounts for only approx. $0.7 \%$ of all primary malignant tumors at the uterine cervix, but the clinical outcome of this type of malignant tumor is better than those of other carcinomas occurring in the uterine cervix [3]. There are some reports of associations between the pathogenesis of lymphoepithelioma-like carcinoma and Epstein-Barr virus (EBV) and with human papilloma virus (HPV).

Here we present a case of lymphoepitheliomalike carcinoma of the uterine cervix that occurred in a Moroccan woman during perimenopause.

\section{Case Representation}

A multiparous, 50-year-old, premenopausal, Moroccan woman was referred to the department of Radiation Oncology of Mohamed VI University
Hospital. She visited another hospital because of postcoital vaginal bleeding that had persisted for three months. The general physical examination was normal. On pelvic examination the cervix was hard, bled to touch, with an ulcerative-budding mass measuring 4 $\mathrm{cm}$, extended to the upper $1 / 3$ of the vagina. Both parametria were involved but not up-to lateral pelvic walls (FIGO stage IIB). The other pelvic organs were normal. Metastatic work-up was negative.

Histopathological examination of the cervical punch biopsy revealed a squamous mucosa seat of a tumor proliferation organized in syncitile masses and lobules. It is made up of undifferentiated, uniform, large cells with strongly nucleolated nuclei with an eosinophilic cytoplasm. They are quite rich in cytonuclear atypia with some mitoses. The stroma is partially fibrous and dense inflammatory, predominantly mononuclear. The tumor is ulcerated on the surface covered with fibrinoleukocytic and haematic material.On immunohistochemical examination, tumour cells were positive for cytokeratin $(\mathrm{CK})$ and epithelial membrane antigen (EMA) and were negative for leukocyte common antigen (LCA) and CD20, thus confirming the diagnosis of LELC. 
A magnetic resonance imaging (MRI) revealed a tumor process of the uterine cervix, roughly oval, of irregular contours, measuring $33 \times 28 \mathrm{~mm}$ and extended over $25 \mathrm{~mm}$, in homogeneous $\mathrm{T} 1$ hyposignal and in intermediate T2 signal, in hypersignal diffusion with extension to the upper third of the vagina. No distant metastatic lesions or enlarged lymph nodes were observed in chest and abdominal computed tomography (CT).

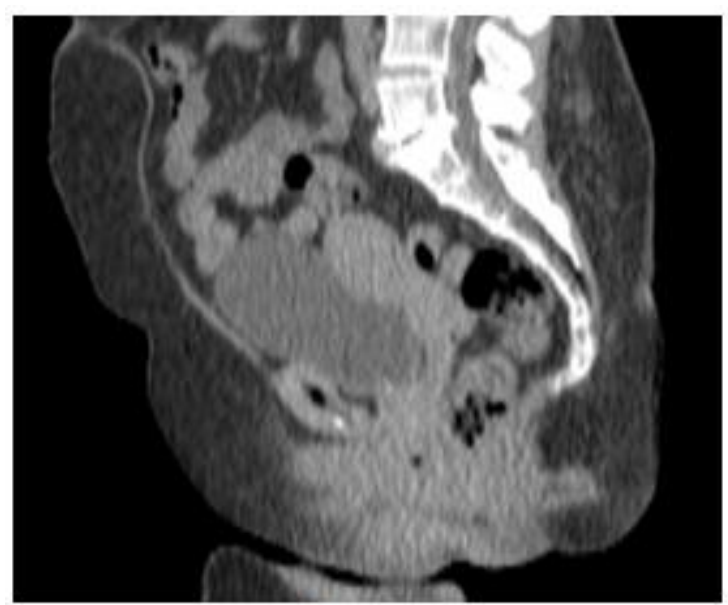

A

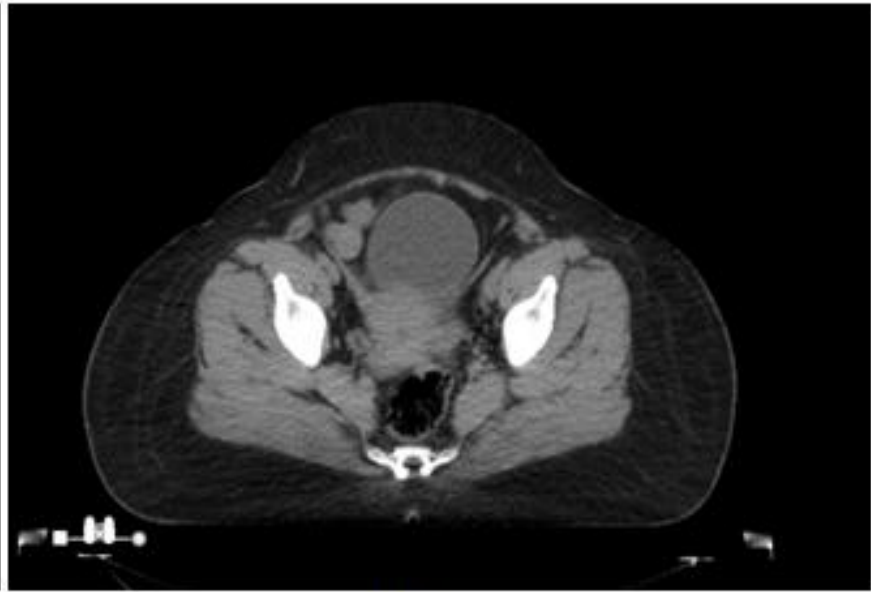

B

Fig-1: Sagittal (A) and axial (B) CT scan images showing cervical carcinoma with invasion of the parametria. CT scan of the pelvis shows inhomogeneous and enlarged cervix with irregular soft-tissue densities extending into the parametria, without invasion of the pelvic sidewalls.

Our patient underwent concurrent chemoradiation: External pelvic radiation 46 Gy (2 Gy/Fraction) + sidewall/parametrial boost, with concurrent cisplatin-based chemotherapy $(35 \mathrm{mg} / \mathrm{m} 2 \mathrm{IV}$ every week for 4 cycles) and High dose-rate (HDR) brachytherapy: 7 Gy per fraction for 4 fractions. The patient has been followed-up without evidence of recurrence or side effects for nine months since her radiotherapy.
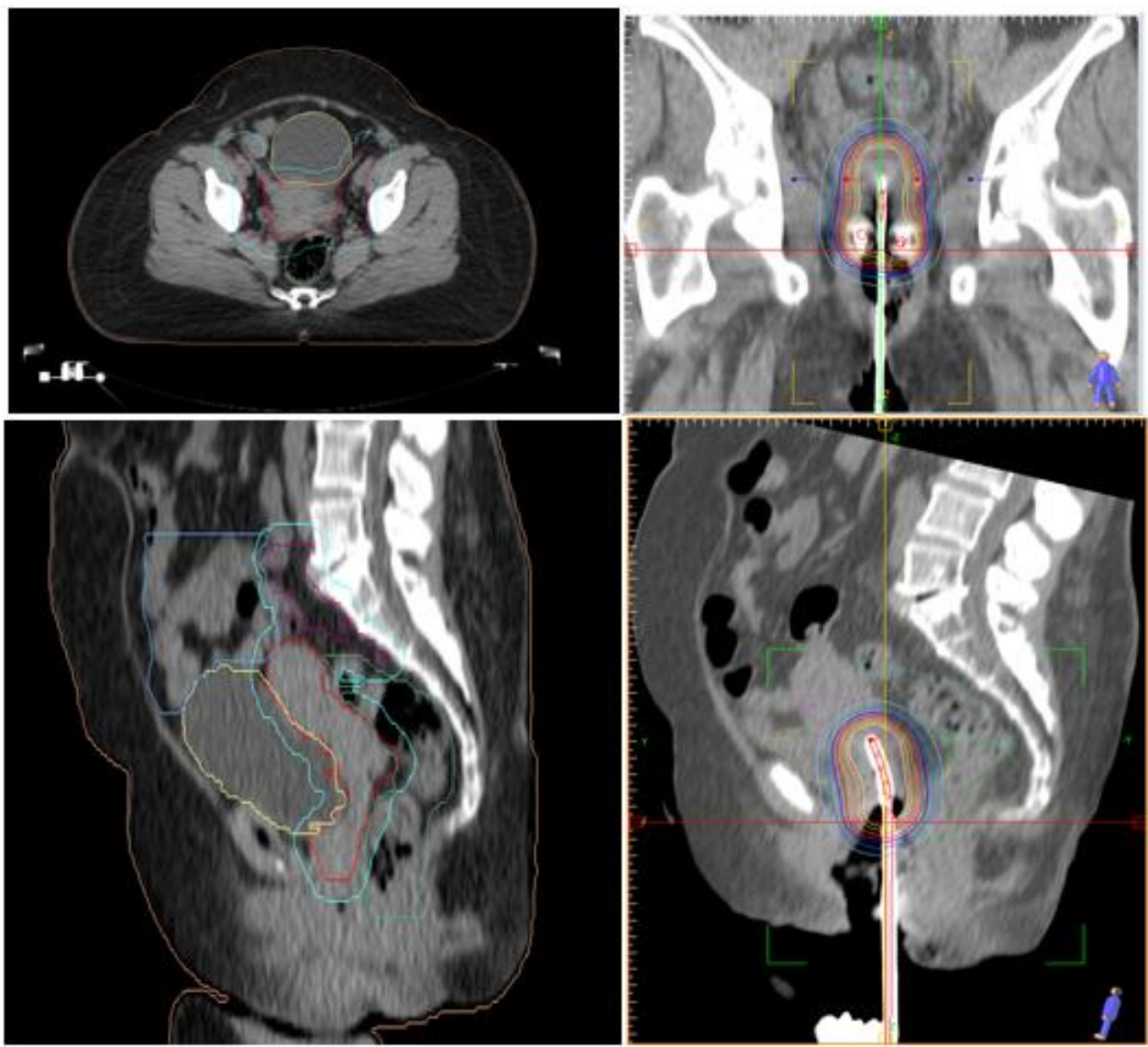


\section{DISCUSSION}

Lymphoepithelioma-like carcinoma appearing in the uterine cervix is an uncommon type of uterine cervical cancer. Generally, this type of tumor is thought to be a subtype of poorly differentiated squamous cell carcinoma, histologically characterized by nests of undifferentiated epithelial cells with a syncytial growth pattern infiltrated by a severe lymphocytic infiltrate. Generally, the mean age of patients with common uterine cancer is from 49 to 54, but that of patients with lymphoepithelioma-like carcinoma occurring in the uterine cervix appears to be younger. Hasumi et al [4] reported that more than $41 \%$ of patients with uterine lymphoepithelioma-like carcinoma were less than 40 years old. In addition, it was reported that uterine lymphoepithelioma-like carcinoma is more common in Asian women compared to West women [1]. The fundamental pathogenesis of lymphoepithelioma-like carcinoma is unknown, but many reports have suggested that EBV has an important role as a causative agent [3]. Tseng et al. [5] reported that 73.3\% (11/15) Asian women with lymphoepithelioma-like carcinoma occurring in the uterine cervix were positive for the antibody of EBV [5]. However, the positive ratio of those patients in Caucasian women in the West is probably lower. Noel et al. [6] reported that EBV had not been detected in Caucasian women with lymphoepithelioma-like carcinoma as of 2001. In their review of uterine lymphoepithelioma-like carcinoma reports, Chao et al. [7] reported that 12 of 43 patients with uterine lymphoepithelioma-like carcinoma were positive for EBV.

However, they found that if only the cases of Asian women are examined, $48 \%$ (12/25) of the women with uterine lymphoepithelioma-like carcinoma were positive for EBV, whereas $0 \%$ of the 9 patients of American and Spanish descent were positive for EBV. Thus racial and geographic factors might influence the pathogenesis of lymphoepithelioma- like carcinoma [7]. Some researchers have reported that HPV may be associated with lymphoepitheliomalike carcinoma. HPV is well recognized as an etiological factor in the pathogenesis of uterine cervical cancer. Noel et al. [6] reported that HPV-16 and HPV-18 infection was detected in two Caucasian women with lymphoepithelioma- like carcinoma in the uterine cervix. Bais et al. [8] reported that HPV-16 and HPV45 infection was present in their patient. We did not check the existence or non-existence of HPV infection in the present case, because the lesion of squamous cell carcinoma was mixed with that of lymphoepitheliomalike carcinoma, and thus HPV infection was strongly suspected in this case.

Several researchers reported that the prognosis of lymphoepithelioma-like carcinoma is better than those of other types of cervical cancer such as common squamous cell carcinoma and adenocarcinoma [4, 8]. Van Nagell et al. [9] reported that uterine lymphoepithelioma-like carcinoma has less lymphocytic metastasis and tumor recurrence compared to common uterine cancers such as common squamous cell carcinoma and adenocarcinoma. Moreover, Hasami et al. [4] found that the 5-year survival of patients is also better in uterine lymphoepithelioma-like carcinoma compared to other squamous cell carcinomas.

Only 9 months have passed since the initial treatment, so the patient has been strictly followed-up at our hospital. We have reported a rare case of lymphoepithelioma-like carcinoma of the uterine cervix, stage IIB, FIGO. The patient was treated with CCRT. This type of tumor tends to have a good clinical outcome, but we have been following the patient carefully.

\section{Conclusion}

Cervical LELC is rare but a distinct clinicopathological entity that warrants a high index of suspicion amongst clinicians and pathologists. Immunohistochemistry is important for the confirmation of this diagnosis. Therefore, large-scale research is difficult to conduct. A multicenter, national registration system could be essential for future research about the prognosis and treatment of such a rare disease. Our patient was treated with CCRT. The long disease free status observed in our case is in keeping with other cases reported in literature.

\section{REFERENCES}

1. Takai N, Nakamura S, Goto K, Hayashita C, Kira $\mathrm{N}$, Urabe S, Narahara $\mathrm{H}$, Matsumoto $\mathrm{H}$. Lymphoepithelioma-like carcinoma of the uterine cervix. Archives of gynecology and obstetrics. 2009 Nov 1;280(5):725-7.

2. Hamazaki M, Fujita H, Arata T, Takata S. " Medullary carcinoma with lymphoid infiltration" of the uterine cervix--pathological picture of a case of cervix cancer with a favorable prognosis. Gan no rinsho. Japan journal of cancer clinics. 1968 Sep;14(9):787-92.

4. Kohrenhagen N, Eck M, Höller S, Dietl J. Lymphoepithelioma-like carcinoma of the uterine cervix: absence of Epstein-Barr virus and high-risk human papilloma virus infection. Archives of gynecology and obstetrics. 2008 Feb 1;277(2):1758.

5. Hasumi K, Sugano H, Sakamoto G, Masubuchi K, Kubo H. Circumscribed carcinoma of the uterine cervix, with marked lymphocytic infiltration. Cancer. 1977 Jun;39(6):2503-7.

6. Tseng CJ, Pao CC, Tseng LH, Chang CT, Lai CH, Soong YK, Hsueh S, Jyu- Jen H. Lymphoepithelioma- like carcinoma of the uterine cervix: Association with Epstein- Barr virus and human papillomavirus. Cancer: Interdisciplinary International Journal of the American Cancer Society. 1997 Jul 1;80(1):91-7. 
7. Noel JC, Lespagnard L, Fayt I, Verhest A, Dargent JL. Evidence of human papilloma virus infection but lack of Epstein-Barr virus in lymphoepithelioma-like carcinoma of uterine cervix: report of two cases and review of the literature. Human pathology. 2001 Jan 1;32(1):1358.

8. Chao A, Tsai CN, Hsueh S, Lee LY, Chen TC, Huang SL, Chao FY, Lai CH. Does Epstein-Barr virus play a role in lymphoepithelioma-like carcinoma of the uterine cervix?. International journal of gynecological pathology. 2009 May 1;28(3):279-85

9. Bais AG, Kooi S, Teune TM, Ewing PC, Ansink AC. Lymphoepithelioma-like carcinoma of the uterine cervix: absence of Epstein-Barr virus, but presence of a multiple human papillomavirus infection. Gynecologic oncology. 2005 May 1;97(2):716-8.

10. Van Nagell Jr JR, Donaldson ES, Wood EG, Parker JC. The significance of vascular invasion and lymphocytic infiltration in invasive cervical cancer. Cancer. 1978 Jan;41(1):228-34. 